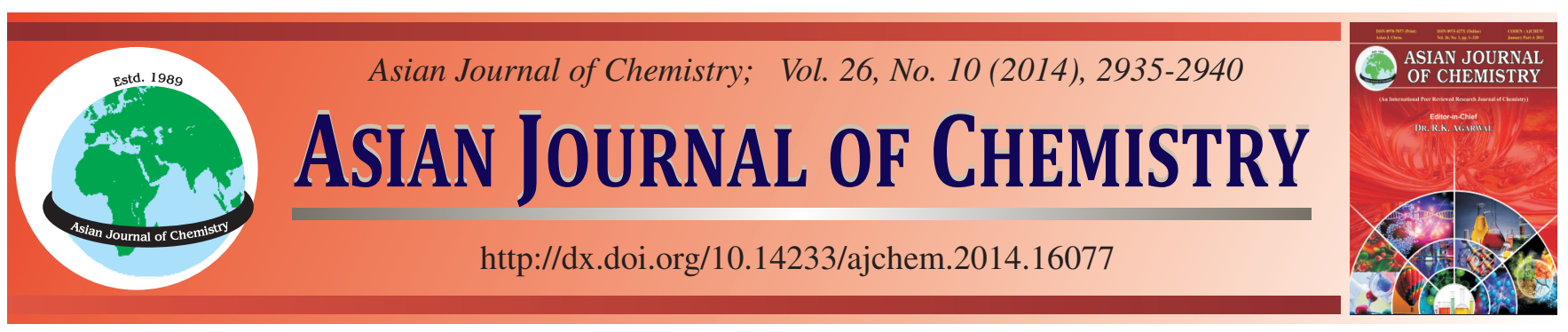

\title{
Optimization of Kinetic Method for the Estimation of N-Acetyl L-Cysteine and Characterization of its Oxidation and Degradation Product by Mass Spectrometry
}

\author{
Masoom Raza Siddiqui ${ }^{1, *}$, Zeid Abdullah Alothman ${ }^{1}$, Saikh Mohammad Wabaidur $^{1}$, \\ Md. SAJid Ali ${ }^{2}$, Md SARFAraz Alam² and Taieb Aouak ${ }^{1}$
}

${ }^{1}$ Chemistry Department, College of Science, King Saud University, Riyadh, Saudi Arabia

${ }^{2}$ College of Pharmacy, Jazan University, Jazan, Saudi Arabia

*Corresponding author: Fax: +966 14675992; Tel: +966 14674198; E-mail: siddiqui124@ gmail.com

\begin{abstract}
A simple kinetic spectrophotometric method has been developed and validated for the quantitative analysis of N-acetyl L-cysteine. The proposed method is based on the oxidation of $\mathrm{N}$-acetyl L-cysteine by potassium permanganate. The mechanism of the reaction was studied and the reaction product was subjected to mass spectrometric analysis for characterization. By the spectral analysis it was concluded that the oxidation of $\mathrm{N}$-acetyl L-cysteine resulted in the formation of a disulfides, sulfinic acid and sulphonic acid. Two methods, initial rate and fixed time were adopted to quantitate the drug. The method was validated as per the ICH guidelines. The calibration graph obtained by the current methods was found to be linear in the range of 3.5-77 $\mu \mathrm{g} \mathrm{mL}^{-1}$. The detection limit of the initial rate and the fixed time methods was calculated to be $8.5 \times 10^{-3}$ and 0.456 , respectively while the quantitation limit came out to be $2.59 \times 10^{-3}$ and 0.140 , respectively for the initial rate and fixed time methods.
\end{abstract}

Keywords: N-Acetyl L-cysteine, Analytical method, Degradation product, Mass spectrometry.

\section{INTRODUCTION}

$\mathrm{N}$-Acetyl-L-cysteine (NAC) is a drug primarily used as a mucolytic agent in respiratory disorder and in the management of acetaminophenpoisoning ${ }^{1}$. The treatment of mucus is based on the breaking disulfide bonds in proteins.It is also used as a nutritional supplement claiming to have antioxidant and liver protective effects. Chemically it is known as 2-acetamido-3sulfanylpropanoic acid. N-Acetyl-L-cysteine is also involved in increasing the level of glutathione that is an antioxidant involved in many biological process in the human body ${ }^{2}$. One of the important applications of N-acetyl-L-cysteine is its function as metal chelating drug for several toxic metals boron, cadmium, cobalt, arsenic and lead ${ }^{3,4}$. Several analytical methods have been reported in the literature for the determination in variety of matrices; including spectrophotometry ${ }^{5-7}$, potentiometry ${ }^{1,8-10}$, fluorimetry ${ }^{11}$, high performance liquid chromatography $^{12,13}$. In the literature, a single kinetic method has been reported for analysis of $\mathrm{N}$-acetyl-L-cysteine that too include the application of buffer thus making the determination process a little bit lengthy. Therefore, a simple method is required to evaluate $\mathrm{N}$-acetyl-L-cysteine in its dosage form kinetically. Similar type of reaction mechanism is reported in the literature for the quantitative analysis of different molecules ${ }^{14,15}$. The proposed method is simple, rapid and can be adapted to both bulk drug and dosage forms. Moreover, it does not require expensive instrumentation except for the characterization of oxidation product.

\section{EXPERIMENTAL}

The absorbance measurements during the drug determination process were made on Evolution 300, thermo UV-visible spectrophotometer, with matching quartz cells. Reaction time was 12 min and reaction temperature $25^{\circ} \mathrm{C}$.

Reagents and standards: The studied drug, N-acetyl-Lcysteine was purchased from Merck, Damstadt and was used as received. All other reagents were of analytical grade and water used throughout the experiment was from the Milli Q water system. The solution of potassium permanganate 6.58 $\times 10^{-3} \mathrm{M}$ and sodium hydroxide $0.05 \mathrm{M}$ was prepared in water. Marketed dosage form of N-acetyl-L-cysteine used in the determination process was Mucomelt (Venus Remedies Limited) and Mucinac (Cipla). The market dosage form of N-acetyl-Lcysteine was purchased from the Indian market.

Stock solution: A stock solution of $\mathrm{N}$-acetyl-L-cysteine was prepared by dissolving $35 \mathrm{mg}$ of the drug in $50 \mathrm{~mL}$ Milli $\mathrm{Q}$ water. Other concentrations were prepared by diluting the stock solution further. The stock and the diluted solutions were found to be stable for 3 days. 


\section{General procedure}

Initial rate method: Aliquot solutions equivalent to 3.5 $77 \mu \mathrm{g} \mathrm{mL}-1$ of standard N-acetyl-L-cysteine solutions were transferred to a series of the standard flasks. $2 \mathrm{~mL}$ of potassium permanganate followed by $2.3 \mathrm{~mL}$ of sodium hydroxide were then added to the standard flask containing the drug. The mixture of the flask was mixed well and made upto the volume with Milli Q water. The spectrophotometric assessment of the mixture showed an increase in absorbance and the best absorbance was observed at $605 \mathrm{~nm}$. The same wavelength was set to record the absorbance of the drug product as a function of time. The calibration plot of initial rate of reaction versus log of the molar concentration of $\mathrm{N}$-acetyl-L-cysteine was prepared to evaluate the concentration of the drug.

Fixed time method: The absorbance of each reaction mixture containing the $\mathrm{N}$-acetyl-L-cysteine, potassium permanganate and the sodium hydroxide in the similar concentration mentioned in the initial rate method in the $12^{\text {th }}$ min of the study was recorded and calibration graph of absorbance was plotted against the concentration of the drug. The quantitative assessment of the drug can be done either from the calibration graph or from the linear regression equation.

Procedure of quantitative evaluation of the studied drug in pharmaceutical dosage form: Accurately weighed quantity of the tablet and its content equivalent to $700 \mathrm{mg}$ were transferred into a $1000 \mathrm{~mL}$ volumetric flask and completed to the mark with Milli Q water. The content of the volumetric flask was sonicated for 10 minutes and filtered. The amounts of the drug equivalent to $3.5-77 \mu \mathrm{g} \mathrm{mL} \mathrm{m}^{-1}$ were taken and above procedures were applied. The nominal amount of the $\mathrm{N}$-acetylL-cysteine was calculated by the desired procedure either from the calibration plot or from the linear regression equation.

\section{RESULTS AND DISCUSSION}

Oxidation of $\mathrm{N}$-acetyl-L-cysteine was performed with potassium permanganate in the presence of $\mathrm{NaOH}$. The trials were performed to determine $\mathrm{N}$-acetyl-L-cysteine through the potassium permanganate oxidation in both the neutral and the acidic medium but apparently no colored product was observed leading to the determination process. The drug's oxidation was possible when potassium permanganate was made to react with the $\mathrm{N}$-acetyl-L-cysteine in the presence of $\mathrm{NaOH}$ and a green colored product was formed which was due to the formation of manganate ion. Fig. 1 shows that the aqueous solution of the $\mathrm{N}$-acetyl-L-cysteine, when subjected to spectrophotometric scan showed maximum absorption at $208 \mathrm{~nm}$ while the reagent have a $\lambda_{\max }$ of $530 \mathrm{~nm}$. When the drug was mixed with the reagent, green colour is formed which absorbs maximally at $605 \mathrm{~nm}$. The intensity of the green colored compound increased with an increase in the time and became constant after $40 \mathrm{~min}$. Other oxidants tried for the method development process were chloramine $\mathrm{T}$ and $10 \%$ hydrogen peroxide. N-Acetyl-Lcysteine when subjected to reaction with chloramine $\mathrm{T}$ in various mediums did not yield any results while that with $\mathrm{H}_{2} \mathrm{O}_{2}$ gave precipitate showing the decomposition of the drug.

Mechanism of the oxidation of $\mathrm{N}$-acetyl-L-cysteine: The mechanism of the reaction is based on one of the important reactions of biochemistry where the oxidation of aliphatic

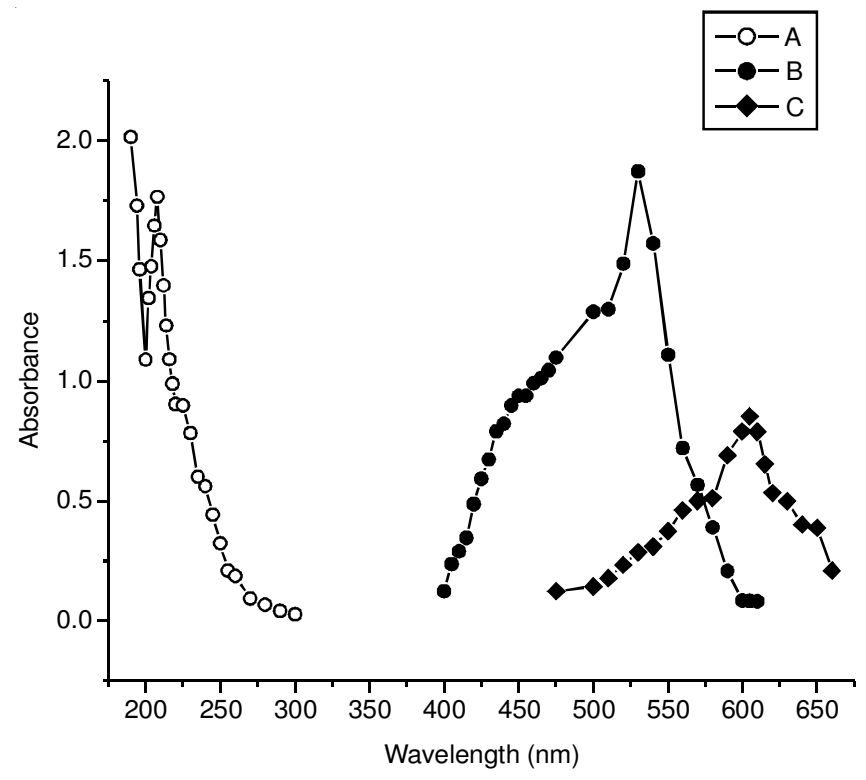

Fig. 1. Absorption spectra of (A) $1.07 \times 10^{-5} \mathrm{M}$ N-acetyl-L-cysteine (B) $1.45 \times 10^{-5} \mathrm{M} \mathrm{KMnO}_{4}+1.15 \times 10^{-2} \mathrm{M} \mathrm{NaOH}(\mathrm{C}) 1.45 \times 10^{-5} \mathrm{M}$ $\mathrm{KMnO}_{4}+1.15 \times 10^{-2} \mathrm{M} \mathrm{NaOH}+4.29 \mathrm{E}-04 \mathrm{M} \mathrm{N}$-acetyl-L-cysteine

thiol takes place. In the aliphatic thiols oxidation process the aliphatic thiols undergo oxidative dimerization to give three types of compounds first the disulfides (RSSR) or the sulfinic acid $\left(\mathrm{RSO}_{3} \mathrm{H}\right)$ or the sulphonic acid $\left(\mathrm{RSO}_{3} \mathrm{H}\right)^{16}$. The studied molecule $\mathrm{N}$-acetyl-L-cysteine comes from the amino acid Lacetyl cysteine undergoes oxidation by potassium permanganate in basic medium. In this study $\mathrm{N}$-acetyl cysteine having a thiol group in it moiety, upon oxidation from all the three types of oxidation product namely disulfides, sulfinilic acid and sulphonic acid. This was confirmed by the evaluation of the oxidation product by mass spectrometry. The $\mathrm{m} / \mathrm{z}$ ratio of the pure drug comes at 162 in negative mode (Fig. 2). The mass spectrometric analysis of the oxidation product shows the formation of product at $\mathrm{m} / \mathrm{z} 323,210$ and 196 corresponding to disulfides, sulfinilic acid and sulphonic acid (Fig. 3). The operating conditions for the characterization of the pure Nacetyl-L-cysteine and oxidation and the degradation product are mentioned in Table-1.

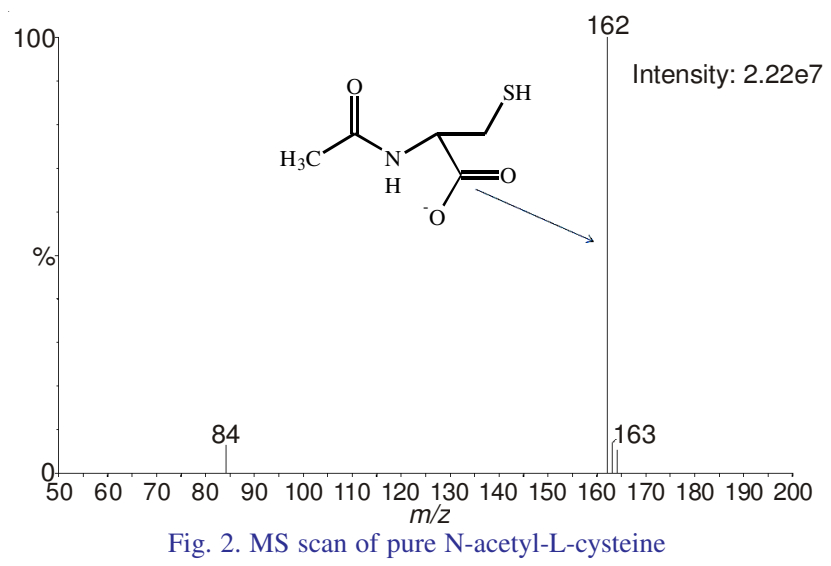

\section{Study of experimental factors}

Effect of potassium permanganate and sodium hydroxide: The impact of potassium permanganate on the initial 


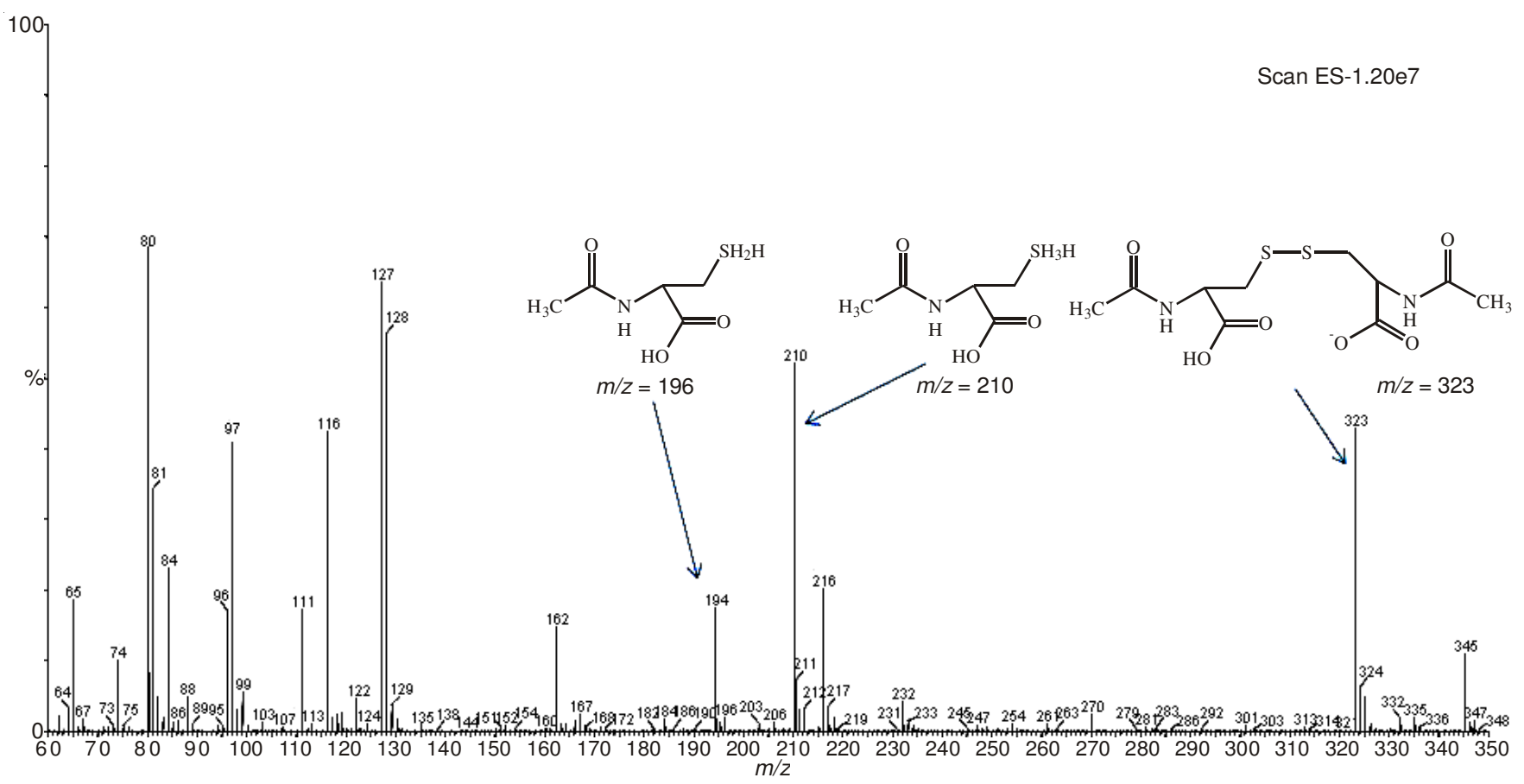

Fig. 3. MS scan of the oxidation product of N-Acetyl L-cysteine

\begin{tabular}{lc}
\multicolumn{2}{c}{ TABLE-1 } \\
\multicolumn{2}{c}{$\begin{array}{c}\text { ESI-MS/MS CONDITIONS FOR CHARACTERIZATION } \\
\text { OF PURE, OXIDATION PRODUCT AND REACTION }\end{array}$} \\
\multicolumn{1}{|c}{ PRODUCT OF N-ACETYL L-CYSTEINE } \\
\hline Items & Parameters \\
\hline Polarity & ESI \\
Capillary voltage & $3.0(\mathrm{KV})$ \\
Cone voltage & $-50(\mathrm{~V})$ \\
Source temperature & $120^{\circ} \mathrm{C}$ \\
Desolvation temperature & $300^{\circ} \mathrm{C}$ \\
Desolvation gas flow & $600 \mathrm{~L} / \mathrm{h}$ \\
Cone gas flow & $60 \mathrm{~L} / \mathrm{h}$ \\
\hline
\end{tabular}

rate of reaction was evaluated using different volumes of 6.58 $\times 10^{-3} \mathrm{M}$ in the concentration range of $6.58 \times 10^{-5}-1.65 \times 10^{-3}$. It was observed that the initial rate of reaction increased with the increase in the concentration of $\mathrm{KMnO}_{4}$. However, the initial rate became constant at $1.25 \times 10^{-3} \mathrm{M}$ and remained as such upto $1.65 \times 10^{-3} \mathrm{M}$. Therefore, a concentration of $1.32 \times$ $10^{-3} \mathrm{M}$ was taken in the assay process.

The influence of sodium hydroxide on the rate of reaction was also studied which showed that the initial rate of reaction increase with increasing the concentration of $\mathrm{NaOH}$ from 2.5 $\times 10^{-4} \mathrm{M}$ to $1.0 \times 10^{-2} \mathrm{M}$ and remained unchanged upto $1.25 \times$ $10^{-2} \mathrm{M}$. Thus, $1.15 \times 10^{-2} \mathrm{M}$ of $\mathrm{NaOH}$ was selected for the determination process.

Evaluation of the kinetic parameters: As the reaction of $\mathrm{N}$-acetyl-L-cysteine with potassium permanganate reach to completion after $40 \mathrm{~min}$, kinetic method was exploited for its determination. The kinetic studies were performed under the pseudo-first order conditions at $25 \pm 1{ }^{\circ} \mathrm{C}$. The initial rate of reaction was established from the graph of absorbance versus time (Fig. 4) by determining the slope of the initial tangent of the same graph and is summarized in Table-2.

The kinetic equation of the $\mathrm{N}$-acetyl-L-cysteine oxidation by $\mathrm{KMnO}_{4}$ in basic medium can be written as.

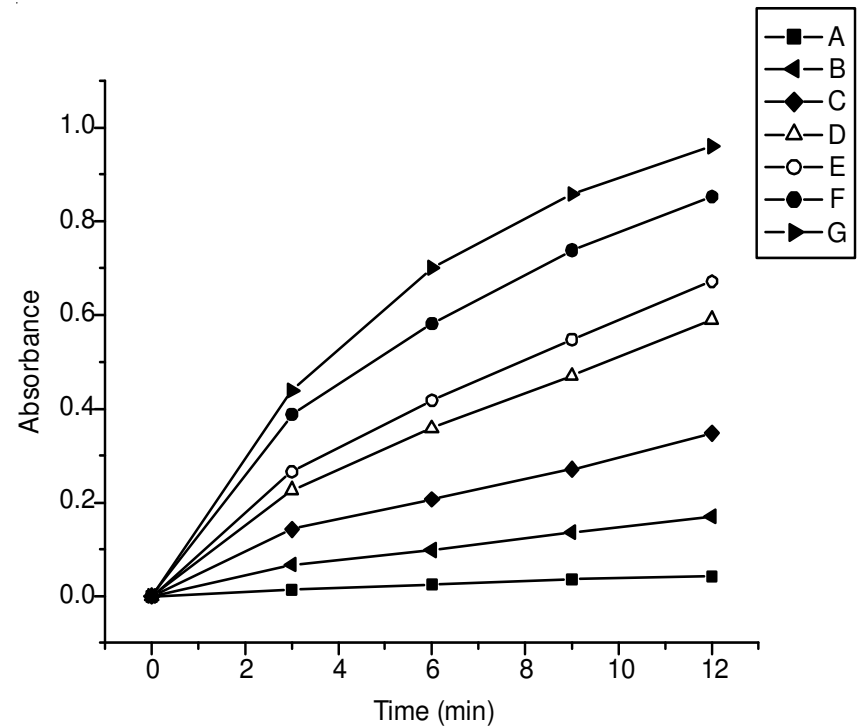

Fig. 4. Absorbance-time plot of oxidation of N-Acetyl-L-cysteine with $\mathrm{KMnO}_{4}$ in alkaline medium: $1.32 \times 10^{-3} \mathrm{M} \mathrm{KMnO}_{4}$ (A) $2.15 \times 10^{-5}$ (B) $8.50 \times 10^{-5}$ (C) $1.72 \times 10^{-4}$ (D) $3.0 \times 10^{-4}$ (E) $3.43 \times 10^{-4}$ (F) 4.29 $\times 10^{-4}(\mathrm{G}) 4.72 \times 10^{-4} \mathrm{M}$ N-acetyl-L-cysteine

TABLE-2

INITIAL RATE OF REACTION AT DIFFERENT CONCENTRATION OF N-ACETYL L-CYSTEINE KEEPING $\left[\mathrm{KMNO}_{4}\right]$ AND [NAOH] CONSTANT

\begin{tabular}{cccc}
\hline $\mathrm{C}\left[\right.$ Drug] mol ${ }^{-1}$ & $\log \mathrm{C}$ & $\begin{array}{c}\text { Initial rate of reaction }(\mathrm{v}) \\
\left(\mathrm{mol} \mathrm{L}^{-1} \mathrm{~S}^{-1}\right)\end{array}$ & $\log \mathrm{v}$ \\
\hline $2.14 \times 10^{-5}$ & -4.668 & 0.0033 & -2.4815 \\
$8.58 \times 10^{-5}$ & -4.067 & 0.0115 & -1.9393 \\
$1.72 \times 10^{-5}$ & -3.765 & 0.0258 & -1.5883 \\
$3.00 \times 10^{-4}$ & -3.522 & 0.0401 & -1.3968 \\
$3.43 \times 10^{-4}$ & -3.464 & 0.0448 & -1.3487 \\
$4.29 \times 10^{-4}$ & -3.368 & 0.0517 & -1.2865 \\
$4.72 \times 10^{-4}$ & -3.326 & 0.0550 & -1.2596 \\
\hline
\end{tabular}




$$
v=\frac{d_{x}}{d_{t}}=K \dagger[C]^{\mathrm{n}}\left[\mathrm{KMnO}_{4}\right]^{\mathrm{m}}[\mathrm{NaOH}]^{1}
$$

For $\left[\mathrm{KMnO}_{4}\right] \geq 6.8 \times 10^{-3} \mathrm{M}$ and $[\mathrm{NaOH}] \geq 5.0 \times 10^{-2} \mathrm{M}$ eqn. 1 thus reduced to

$$
\begin{aligned}
& \frac{\mathrm{d}_{\mathrm{x}}}{\mathrm{d}_{\mathrm{t}}}=\mathrm{K} \dagger \mathrm{C}^{\mathrm{n}} \\
& \text { Rate }=\mathrm{K} \dagger[\mathrm{C}]
\end{aligned}
$$

From the plot of $\log$ of initial rate of reaction $(\log \mathrm{v})$ versus the $\log$ of the molar concentration of $\mathrm{N}$-acetyl-Lcysteine $(\log \mathrm{C})$ the order of reaction with respect to the $\mathrm{N}$ acetyl-L-cysteine was calculated and found to be unity. Therefore, eqn. 2 can be reduced to

$$
v=\frac{d_{x}}{d_{t}}=K \dagger C
$$

where, $\mathrm{K} \dagger$ is the pseudo order rate constant. $\mathrm{C}$ is the concentration of $\mathrm{N}$-acetyl-L-cysteine and $n$ is the order of reaction.

The equation in the logarithmic form can be written as: $\log ($ rate $)=\log \mathrm{K} \dagger+\mathrm{n} \log \mathrm{C}$

Under the experimental condition post optimization, the calibration plot of initial rate versus concentration was established to be in the concentration range of 3.5-77 $\mu \mathrm{g} \mathrm{mL}^{-1}$. The linear regression equation obtained from the plot was $v$ $2.13 \times 10^{-5}$ to $8.5 \times 10^{-5} \mathrm{C}$ with correlation coefficient, $\mathrm{r}=$ 0.9931. The statistical treatment of the yielded the confidence limits of the slope and the intercept of the regression line and was obtained to be $1.70 \times 10^{-5}$ and $4.47 \times 10^{-4}$, respectively. The lower value of the slope and the intercept line shows the high reproducibility of the initial rate method. The detailed regression characteristic of the initial rate method is listed in Table-3.

In the fixed time method, the measurement of the absorbance of the green colored product which was due to the reduction of the potassium permanganate was made for different concentrations of N-acetyl-L-cysteine. For the quantitative analysis of the $\mathrm{N}$-acetyl-L-cysteine the absorbance obtained at 3, 6, 9 and 12 min were plotted against their corresponding time. The key parameters of these calibration plots are mentioned in Table-3. It is evident that the most acceptable value of the linearity can be obtained from data obtained in $12 \mathrm{~min}$. Therefore, a fixed time of 12 min was selected as the ideal time for evaluating the content of $\mathrm{N}$-acetyl-L-cysteine in the pharmaceutical dosage form.
Method validation: Validation of analytical procedure has been a significant feature not just for regulatory commitments, but also for their reliable long-term application and proof of the reliability of the newly developed methods. The parameters for the method validation adapted in this study are

1. Confirmation of identity

2. Solution stability

3. Selectivity/ specificity

4. Linearity

5. Accuracy and precision

6. Limits of detection and quantitation

7. Recovery

8. Robustness

9. Equivalence testing

Confirmation of identity: The compound, N-acetyl-Lcysteine was confirmed using the mass spectrometer. $1 \mathrm{ppm}$ solution of N-acetyl-L-cysteine was infused into the electrospray ionization-mass spectrometry (ESI-MS) in negative mode. The mass spectrum has shown that the major component is having parent mass of 162 . This confirms the compound to be N-acetyl-L-cysteine (Fig. 2).

Solution stability: Stability of the standard N-acetyl-Lcysteine solution was evaluated by recording the UV absorption spectra of the compound for three consecutive days. The drug which showed a $\lambda_{\max }$ of $208 \mathrm{~nm}$ during the spectral studies exhibited the same $\lambda_{\text {max }}$ for both the standard and test solution, when stored at room temperature without exposure to any type of light. Moreover, assay was performed on the standard and the test solution at two storage conditions i.e. at room temperature and at lower temperature $\left(2-8^{\circ} \mathrm{C}\right)$ for $24 \mathrm{~h}$ at an interval of $6 \mathrm{~h}$. The assay results showed that at room temperature the drug degraded to a level of $0.98 \%$ while the degradation percentage of the drug stored at $2-8{ }^{\circ} \mathrm{C}$ was $0.67 \%$.

Specificity: To check the specificity of the current method, the synthetic mixture having N-acetyl-L-cysteine and common excipient used in the tablet formulation was prepared. The prepared mixture contains $\mathrm{N}$-acetyl-L-cysteine ( $25 \mathrm{mg}$ ), lactose (75 mg), starch (100 mg), talc (100 mg) and magnesium stearate $(10 \mathrm{mg})$. The content of the mixture equivalent to $17.5 \mathrm{mg}$ of $\mathrm{N}$-acetyl-L-cysteine was transferred to a $25 \mathrm{~mL}$ flask and the amount of N-acetyl-L-cysteine was calculated. During the

\begin{tabular}{|c|c|c|c|c|c|}
\hline \multirow{3}{*}{ Parameters } & \multicolumn{4}{|c|}{$\begin{array}{l}\text { TABLE-3 } \\
\text { CHARACTERISTICS AND ANALYTICAL DATA OF } \\
\text { TE AND FIXED TIME METHODS (AT 3, } 9 \text { AND } 12 \text { MIN) }\end{array}$} & \multirow{3}{*}{ Initial rate method } \\
\hline & \multicolumn{4}{|c|}{ Fixed time method } & \\
\hline & $3 \mathrm{~min}$ & $6 \mathrm{~min}$ & $9 \min$ & $12 \mathrm{~min}$ & \\
\hline Beer's law range & $3.5-77$ & $3.5-77$ & $3.5-77$ & $3.5-77$ & $3.5-77$ \\
\hline Regression equation & $\begin{array}{c}-1.02 \times 10^{-2}+8.5 \times \\
10^{-3} \mathrm{C}\end{array}$ & $\begin{array}{c}-1.82 \times 10^{-2}+8.38 \times \\
10^{-3} \mathrm{C}\end{array}$ & $\begin{array}{c}-2.17 \times 10^{-2}+1.02 \times \\
10^{-2} \mathrm{C}\end{array}$ & $\begin{array}{c}-6.02 \times 10^{-4}+1.21 \times \\
10^{-2} \mathrm{C}\end{array}$ & $\begin{array}{c}2.13 \times 10^{-5}+8.5 \times \\
10^{-3} \mathrm{C}\end{array}$ \\
\hline Standard Deviation & 0.00148 & 0.00176 & 0.0026 & 0.00519 & $2.20 \times 10^{-3}$ \\
\hline $\mathrm{S}_{\mathrm{a}}$ & $6.1 \times 10^{-2}$ & $1.42 \times 10^{-2}$ & $2.11 \times 10^{-2}$ & $4.21 \times 10^{-3}$ & $1.70 \times 10^{-5}$ \\
\hline $\mathrm{S}_{\mathrm{b}}$ & $3.4 \times 10^{-4}$ & $3.09 \times 10^{-4}$ & $4.59 \times 10^{-4}$ & $9.12 \times 10^{-5}$ & $4.47 \times 10^{-4}$ \\
\hline Correlation coefficient & 0.9938 & 0.9979 & 0.9970 & 0.9999 & 0.9931 \\
\hline Detection limit & 0.91 & 0.69 & 0.838 & 0.46 & $8.53 \times 10^{-3}$ \\
\hline Quantitation limit & 2.76 & 2.10 & 2.54 & 1.40 & $2.59 \times 10^{-2}$ \\
\hline Variance & $2.19 \times 10^{-6}$ & $3.09 \times 10^{-6}$ & $6.76 \times 10^{-6}$ & $2.69 \times 10^{-5}$ & $4.83 \times 10^{-10}$ \\
\hline
\end{tabular}
assay process no interference from the excipients was observed.

Preparation of degradation product and its characterization: The degradation product of $\mathrm{N}$ acetyl-L-cysteine 
was prepared by the reaction of $70 \mu \mathrm{g} \mathrm{mL} \mathrm{m}^{-1} \mathrm{~N}$-acetyl-L-cysteine and $4.11 \times 10^{-2} \mathrm{M}$ potassium iodate in the presence of $0.91 \mathrm{M}$ $\mathrm{H}_{2} \mathrm{SO}_{4}$. The content of the mixture was heated at $80^{\circ} \mathrm{C}$ for 10 min. The N-acetyl-L-cysteine solution turned brownish upon the addition of potassium iodate while the addition of the acid lead to the decomposition of the sample and sediments appeared in the sample but after heating at $80^{\circ} \mathrm{C}$ for $10 \mathrm{~min}$ the sample turned colorless. The reaction product was subjected to mass spectrometric analysis and the product formed was having a mass number similar to that of derivative of sulfinic acid with $\mathrm{m} / \mathrm{z}$ ratio 194 . The spectra of the forced degradation product are shown in Fig. 5.

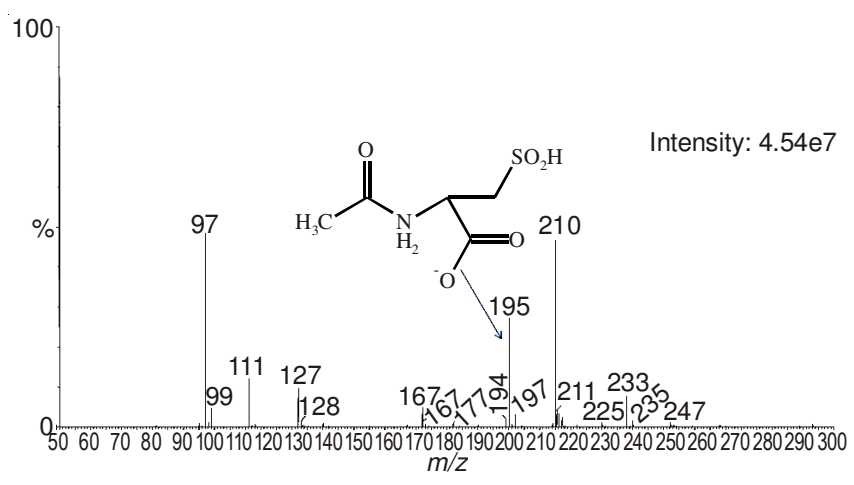

Fig. 5. MS scan of the degradation product of N-acetyl-L-cysteine

Linearity: The linearity parameter of the proposed method was evaluated by determining the content of $\mathrm{N}$-acetyl-L-cysteine at $3.5,14,28,49,56,70$ and $77 \mu \mathrm{g} \mathrm{mL} \mathrm{m}^{-1}$. Each concentration was assayed 5 times.

Accuracy and precision: Intraday assay and interday assay experiments were performed to establish the accuracy and precision of the proposed methods. In this experiment the quantitative content of $\mathrm{N}$-acetyl-L-cysteine was measured at three concentration level for 1 day and for three consecutive days. The Intraday precision was performed by five independent analyses of N-acetyl-L-cysteine at 3.5, 49 and $70 \mu \mathrm{g} \mathrm{mL}$ within 1 day while the interday precision was performed at the same concentration levels for 5 days. For the precision experiments five replicates analyses were performed at each concentration level. The results of the precision experiments are summarized in Table- 4 .

Recovery experiments were performed using the standard addition techniques which are also a tool to check the validity of the proposed methods. In standard addition experiment identified amount of drug is added to the pre-analyzed marketed formulation at three concentration levels by performing five replicate analyses following the recommended procedures for estimation of active drug. The results of standard addition experiments are listed in Table-5. This shows that the methods have excellent recoveries (99.79-101.78) with lower RSD value (0.35-1.91). The results of the recovery experiments also prove that no interference from the common excipients is observed.

Limits of detection (LOD) and quantitation (LOQ): Limit of detection of an analytical method is the point at which the analysis is just achievable while the limit of quantitation is

TABLE-4

EVALUATION OF ACCURACY AND PRECISION OF THE PROPOSED METHOD BY INTRADAY AND INTERDAY ASSAY

\begin{tabular}{|c|c|c|c|c|c|}
\hline Methods & $\begin{array}{l}\text { Amount taken } \\
\left(\mu \mathrm{g} \mathrm{mL}^{-1}\right)\end{array}$ & $\begin{array}{c}\mathrm{RSD}^{\mathrm{a}}(\%) \\
\text { Found } \pm \mathrm{SD}^{\mathrm{a}}\end{array}$ & $\mathrm{SAE}^{\mathrm{b}}$ & C.L. ${ }^{c}$ & Proposed methods \\
\hline \multicolumn{6}{|c|}{ Initial Rate } \\
\hline \multirow[t]{3}{*}{ Intra Day Assay } & 3.5 & $3.55 \pm 0.052$ & 1.480 & 0.023 & 0.070 \\
\hline & 49 & $48.69 \pm 0.586$ & 1.200 & 0.262 & 0.728 \\
\hline & 70 & $70.03 \pm 0.448$ & 0.640 & 0.200 & 0.557 \\
\hline \multirow[t]{3}{*}{ Interday Assay } & 3.5 & $3.47 \pm 0.064$ & 1.850 & 0.029 & 0.080 \\
\hline & 49 & $49.11 \pm 0.933$ & 1.900 & 0.410 & 1.160 \\
\hline & 70 & $70.15 \pm 0.910$ & 1.290 & 0.407 & 1.130 \\
\hline \multicolumn{6}{|c|}{ Fixed Time method } \\
\hline \multirow{3}{*}{ Intra Day Assay } & 3.5 & $3.49 \pm 0.060$ & 1.640 & 0.026 & 0.071 \\
\hline & 49 & $48.63 \pm 0.340$ & 0.700 & 0.152 & 0.421 \\
\hline & 70 & $69.60 \pm 0.289$ & 0.420 & 0.129 & 0.360 \\
\hline \multirow[t]{3}{*}{ Interday Assay } & 3.5 & $3.50 \pm 0.068$ & 1.940 & 0.030 & 0.084 \\
\hline & 49 & $48.68 \pm 0.397$ & 0.820 & 0.178 & 0.494 \\
\hline & 70 & $69.97 \pm 0.452$ & 0.650 & 0.202 & 0.560 \\
\hline
\end{tabular}

${ }^{a}$ Mean of five independent analyses, SAE, Standard analytical error, C.L. Confidence limit at $95 \%$ confidence level and four degrees of freedom $(\mathrm{t}=2.776)$

TABLE-5

STANDARD ADDITION METHOD FOR THE DETERMINATION OF N-ACETYL-L-CYSTEINE IN COMMERCIAL DOSAGE FORM

\begin{tabular}{|c|c|c|c|c|c|c|c|c|c|c|c|c|}
\hline \multirow[b]{2}{*}{$\begin{array}{l}\text { Formu- } \\
\text { lations }\end{array}$} & \multicolumn{6}{|c|}{ Initial rate method } & \multicolumn{6}{|c|}{ Fixed time $(\Delta \mathrm{A})$ method } \\
\hline & $\begin{array}{c}\text { Amount } \\
\text { taken } \\
\left(\mu \mathrm{g} \mathrm{mL}^{-1}\right)\end{array}$ & $\begin{array}{c}\text { Amount } \\
\text { added } \\
\left(\mu \mathrm{g} \mathrm{mL}^{-1}\right)\end{array}$ & $\begin{array}{l}\text { Found } \pm \\
\text { SD }\end{array}$ & $\begin{array}{c}\text { Recovery } \\
(\%)\end{array}$ & $\begin{array}{l}\text { RSD } \\
(\%)\end{array}$ & SAE & $\begin{array}{c}\text { Amount } \\
\text { taken } \\
\left(\mu \mathrm{g} \mathrm{mL}^{-1}\right)\end{array}$ & $\begin{array}{c}\text { Amount } \\
\text { added } \\
\left(\mu \mathrm{g} \mathrm{mL}^{-1}\right)\end{array}$ & $\begin{array}{l}\text { Found } \pm \\
\text { SD }\end{array}$ & $\begin{array}{c}\text { Recovery } \\
(\%)\end{array}$ & $\begin{array}{c}\mathrm{RSD} \\
(\%)\end{array}$ & SAE \\
\hline \multirow{3}{*}{ Mucomelt } & 7 & 7 & $14.07 \pm 0.17$ & 100.50 & 1.19 & 0.07 & 7 & 7 & $14.24 \pm 0.22$ & 101.80 & 1.55 & 0.10 \\
\hline & 7 & 28 & $35.17 \pm 0.40$ & 100.51 & 1.14 & 0.18 & 7 & 28 & $34.94 \pm 0.12$ & 99.83 & 0.35 & 0.05 \\
\hline & 7 & 49 & $56.04 \pm 0.64$ & 100.09 & 1.14 & 0.29 & 7 & 49 & $56.06 \pm 0.92$ & 100.10 & 1.63 & 0.41 \\
\hline \multirow{2}{*}{ Mucinac } & 7 & 7 & $13.99 \pm 0.22$ & 100.00 & 1.58 & 0.01 & 7 & 7 & $14.25 \pm 0.23$ & 101.78 & 1.63 & 0.29 \\
\hline & 7 & 49 & $55.88 \pm 0.94$ & 99.79 & 1.68 & 0.42 & 7 & 49 & $56.23 \pm 1.07$ & 100.41 & 1.91 & 0.48 \\
\hline
\end{tabular}


TABLE-6

POINT AND INTERVAL HYPOTHESIS TESTS: COMPARISON OF THE PROPOSED METHOD WITH THE REFERENCE METHOD

\begin{tabular}{|c|c|c|c|c|c|c|c|c|c|c|c|c|c|c|}
\hline \multirow{3}{*}{ Formulation } & \multicolumn{6}{|c|}{ Point hypothesis test } & \multicolumn{8}{|c|}{ Interval hypothesis test } \\
\hline & \multicolumn{2}{|c|}{ Initial rate method } & \multicolumn{2}{|c|}{$\begin{array}{l}\text { Fixed time } \\
(\Delta \mathrm{A}) \text { method }\end{array}$} & \multicolumn{2}{|c|}{ Reference method } & \multicolumn{4}{|c|}{ Initial rate method } & \multicolumn{4}{|c|}{ Fixed time method } \\
\hline & Recovery & $\begin{array}{l}\mathrm{RSD}^{\mathrm{a}} \\
(\%)\end{array}$ & Recovery & $\begin{array}{l}\mathrm{RSD}^{\mathrm{a}} \\
(\%)\end{array}$ & Recovery & $\begin{array}{l}\mathrm{RSD}^{\mathrm{a}} \\
(\%)\end{array}$ & $\begin{array}{c}\mathrm{t}- \\
\text { value }\end{array}$ & $\begin{array}{c}\mathrm{F}- \\
\text { value }\end{array}$ & $\theta_{\mathrm{L}}$ & $\theta_{\mathrm{U}}$ & $\begin{array}{c}\mathrm{t}- \\
\text { value }\end{array}$ & $\begin{array}{c}\mathrm{F}- \\
\text { value }\end{array}$ & $\theta_{\mathrm{L}}$ & $\theta_{\mathrm{U}}$ \\
\hline Mucomelt & 100.03 & 0.76 & 100.07 & 1.83 & 100.04 & 1.82 & 0.352 & 0.010 & 0.999 & 1.001 & 1.189 & 0.001 & 0.999 & 1.001 \\
\hline Mucinac & 100.07 & 1.02 & 100.08 & 1.87 & 100.06 & 1.80 & 0.847 & 0.006 & 0.999 & 1.001 & 0.696 & 0.002 & 0.999 & 1.001 \\
\hline
\end{tabular}

${ }^{\mathrm{a}}$ Mean of five independent analyses.

the minimum concentration at which quantitative results can be determined with highest accuracy. LOD and LOQ were calculated by the statistical handling of the calibration data by the following equation ${ }^{17}$.

$$
\mathrm{LOD}=3.3 \times \mathrm{S}_{0} / \mathrm{b} \quad \mathrm{LOQ}=10 \times \mathrm{S}_{0} / \mathrm{b}
$$

where, $\mathrm{S}_{0}$ is the standard deviation and $\mathrm{b}$ is the slope of the calibration line. Limit of detection for the initial rate method and the fixed time method was calculated to be 0.456 and 8.5 $\times 10^{-3}$, respectively. Similarly the LOQ for initial rate and the fixed time method was found to be 1.38 and $2.59 \times 10^{-2}$, respectively. Variance was also calculated and found to be 2.89 $\times 10^{-6}$ and $4.83 \times 10^{-10}$ for initial rate and fixed time methods, respectively. The low value of the variance shows that there is negligible scattering of the investigative data points around the line of regression.

Robustness: To check the robustness of the proposed method each operational parameter was tested. The operational parameters investigated were as follows.

Volume of $6.58 \times 10^{-3} \mathrm{M} \mathrm{KMnO}_{4}( \pm 0.3 \mathrm{ML})$

Volume of $0.05 \mathrm{M} \mathrm{NaOH}( \pm 0.3 \mathrm{ML})$

Under these varied conditions two dosages from having $70 \mu \mathrm{g} \mathrm{ml}^{-1}$ of $\mathrm{N}$-acetyl-L-cysteine was analyzed for its content by initial rate and fixed time methods. The results obtained indicate a good sensitivity and excellent recovery. Thus the proposed experimental conditions of the proposed methods are robust.

Applicability of the proposed method: The two proposed methods were applied to determine $\mathrm{N}$-acetyl-L-cysteine in marketed formulations. As a part of equivalence testing the results of the proposed methods were compared to those of the reference method using the point and the interval hypothesis test ${ }^{18}$. The results of which are summarized in Table-6. From the table it is evident that t-value and the F value at $95 \%$ confidence level are within the limits of their theoretical values $^{19}$. This indicates no significant difference between the proposed and the reference method ${ }^{20}$. It is also evident from the Table- 6 that true bias of all samples of the N-acetyl-Lcysteine is smaller than $\pm 2 \%$. This proves that the method is reliable with acceptable recovery as per the guidelines of the Canadian health protection branch ${ }^{21}$ which allows a bias of \pm $2 \%$ where the acceptable limit falls within $\theta_{\mathrm{L}}=0.98$ and $\theta_{\mathrm{U}}=$ 1.02 .

\section{Conclusion}

The current methods exploit the oxidizing property of the potassium permanganate to oxidize $\mathrm{N}$-acetyl-L-cysteine in basic medium for the routine quality control analysis of the drug. The method is simple and do not require any pretreatment prior to the analyses. The oxidation product is validated by mass spectrometry analysis. The determining technique is simple and of low cost. Thus the methods can be used frequently in the quality control laboratories, academic institutions and pharmaceutical industries.

\section{ACKNOWLEDGEMENTS}

The authors extended their appreciation to the Deanship of Scientific Research at King Saud University for funding the work through the research group project No. RGP-VPP-025.

\section{REFERENCES}

1. G.SKelly, Altern. Med. Rev., 3, 114 (1998).

2. A. Prkic, J. Giljanovic and M. Bralic, Int. J. Electrochem. Sci., 6, 5388 (2011).

3. W. Banner Jr., M. Koch, D.M. Capin, S.B. Hopf, S. Chang and T.G. Tong, Toxicol. Appl. Pharmacol., 83, 142 (1986).

4. H. Ottenwa"lder and P. Simon, Arch. Toxicol., 60, 401 (1987)

5. L. Kukoc-Modun and N. Radic, Anal. Sci., 26, 491 (2010).

6. L. Kukoc-modun, N.Radic, Int. J. Anal. Chem., Article ID 140756 (2011).

7. M.C.G. Alvarez-Coque, M.J.M. Hernandez, R.M.V. Camanas and C.M. Fernandez, Analyst, 114, 975 (1989).

8. A. Martinovic and N. Radic, Anal. Lett., 40, 2851 (2007).

9. A. Martinovic and N. Radic, Acta Chim. Slov., 56, 503 (2009).

10. M. Kolar and D. Dobcnik, Pharmazie, 58, 25 (2003).

11. M. Al-Ghannam, A.M. El-Brashy and B.S. Al-Farhan, IL Farmaco, 57, 625 (2002).

12. W. Wu, G. Goldstein, C. Adams, R.H. Matthews and N. Ercal, Biomed. Chromatogr., 20, 415 (2006).

13. M.P. Bartolomeo and F. Maisano, J. Biomol. Tech., 17, 131 (2006).

14. Z.A. Alothman, M.R. Siddiqui, S.M. Wabaidur, H.A. Al-Lohedan, M.S. Ali and M.Z.A. Rafiquee, Asian J. Chem., 25, 4563 (2013).

15. Z.A. Alothman, M.R. Siddiqui and M.A. Khan, Asian J. Chem., 25, 7229 (2013).

16. P. Sami, N. Mariselvi, K. Venkateshwari, A. Sarathi and K. Rajasekaran, J. Chem. Sci., 122, 335 (2010).

17. J. Ermer, J. Pharm. Biomed. Anal., 24, 755 (2001).

18. C. Hartmann, J. Smeyers-Verbeke, W. Penninckx, Y. Vander Heyden, P. Vankeerberghen and D.L. Massart, Anal. Chem., 67, 4491 (1995).

19. G.D. Christian, Analytical Chemistry, John Wiley \& Sons, Inc., Singapore, p. 90 (2004).

20. M. Abu Eid, Mikrochim. Acta, 129, 91 (1998).

21. Canada Health Protection Branch, Drugs Directorate Guidelines, Acceptable Methods, Ministry of National Health and Welfare, Draft (1992). 